\title{
Principle of restoration ecology reflected in the process creating the National Institute of Ecology
}

\author{
A. Reum Kim, Bong Soon Lim', Jaewon Seol ${ }^{1}$ and Chang Seok Lee ${ }^{2^{*}}$ (D)
}

\begin{abstract}
Background: The creation of the National Institute of Ecology began as a national alternative project to preserve mudflats instead of constructing the industrial complexes by reclamation, and achieve regional development. On the other hand, at the national level, the research institute for ecology was needed to cope with the worsening conditions for maintaining biodiversity due to accelerated climate change such as global warming and increased demand for development. In order to meet these needs, the National Institute of Ecology has the following objectives: (1) carries out studies for ecosystem change due to climate change and biodiversity conservation, (2) performs ecological education to the public through exhibition of various ecosystem models, and (3) promotes regional development through the ecological industry. Furthermore, to achieve these objectives, the National Institute of Ecology thoroughly followed the basic principles of ecology, especially restoration ecology, in the process of its construction. We introduce the principles and cases of ecological restoration applied in the process.

Results: We minimized the impact on the ecosystem in order to harmonize with the surrounding environment in all the processes of construction. We pursued passive restoration following the principle of ecological restoration as a process of assisting the recovery of an ecosystem degraded for all the space except in land where artificial facilities were introduced. Reference information was applied thoroughly in the process of active restoration to create biome around the world, Korean peninsula forests, and wetland ecosystems. In order to realize true restoration, we pursued the ecological restoration in a landscape level as the follows. We moved the local road 6 and high-voltage power lines to underground to ensure ecological connectivity within the National Institute of Ecology campus. To enhance ecological diversity, we introduced perch poles and islands as well as floating leaved, emerged, wetland, and riparian plants in wetlands and mantle communities around the forests of the Korean Peninsula in the terrestrial ecosystem. Furthermore, in order to make the public aware of the importance of the intact nature, the low-lying landscape elements, which have disappeared due to excessive land use in most areas of Korea, was created by imitating demilitarized zone (DMZ) landscape that has these landscape elements.

Conclusions: The National Institute of Ecology was created in an eco-friendly way by thoroughly reflecting the principles of ecology to suit its status and thus the impact on the existing ecosystem was minimized. This concept was also designed to be reflected in the process of operation. The results have become real, and a result of analysis on carbon budget analysis is approaching the carbon neutrality.
\end{abstract}

Keywords: Biodiversity, Climate change, Landscape ecology, National Institute of Ecology, Passive restoration, Restoration ecology

\footnotetext{
*Correspondence: leecs@swu.ac.kr

${ }^{2}$ Division of Chemistry and Bio-Environmental Sciences, Seoul Women's University, 621 Hwarang-no, Nowon-gu, Seoul 01797, Republic of Korea Full list of author information is available at the end of the article
}

(c) The Author(s). 2021 Open Access This article is licensed under a Creative Commons Attribution 4.0 International License, which permits use, sharing, adaptation, distribution and reproduction in any medium or format, as long as you give appropriate credit to the original author(s) and the source, provide a link to the Creative Commons licence, and indicate if changes were made. The images or other third party material in this article are included in the article's Creative Commons licence, unless indicated otherwise in a credit line to the material. If material is not included in the article's Creative Commons licence and your intended use is not permitted by statutory regulation or exceeds the permitted use, you will need to obtain permission directly from the copyright holder. To view a copy of this licence, visit http://creativecommons.org/licenses/by/4.0/. 


\section{Background}

The damage and destruction of nature by human activities have harmed most other species and causing also adverse effects on humans themselves in various forms. Restoration ecology reverses the trend, providing opportunities for various living things to find new habitats, and suggesting to humans a possibility of escaping from such impacts (Lee and You 2001, Gann and Lamb 2006). Succession, which is a recovery process of nature in a disturbed place, is a good example showing the nature's ability to recreate the ecosystem without any human aid (Walker et al. 2007). Considered the fact, it is judged that the damaged environment is likely to be improved more quickly if a purpose-organized human assistance is supported. Ecological restoration is the process of assisting the recovery of the nature that has been degraded, damaged, or destroyed (SERI 2004, Gann and Lamb 2006, Suding et al. 2015, McDonald et al. 2016, Higgs et al. 2018, Gann et al. 2019).

Human beings are just one species that exists within an ecosystem composed of many living things and their habitat, but they require too much resources and energy compared to the other living things to survive. In order to obtain it, human affects the other living things and ecosystems, sometimes destroying it, while human beings exist and develop civilization. Especially in modern civilization, the rapid population growth and excessive concentration of population in cities has killed many species, polluting and destroying natural ecosystems. By devastating an environment where are also their living quarters, humans face environmental problems, and such environmental problems are already reaching a global scale (Lee and You 2001, Lee 2015).

As the natural environment we have enjoyed for a long time is rapidly changing or disappearing, plants, insects, small animals, and even the sounds of birds that have been singing in the fields and water are moving away from humans. However, humans cannot maintain a separate life from the ecosystem, which consists of a combination of other creatures and their surroundings, as long as it is a species. Mankind can survive only by coexisting with nature and maintaining a harmonious relationship with various natures (Lee and You 2001).

Restoration ecology is an ecological technology that aims to secure the future environment of mankind by providing habitat to various living things by healing nature that has been damaged by humans by imitating the integrate system and function of nature (Aronson et al. 1993, Berger 1993, National Research Council 1991, SERI 2004, Suding et al. 2015, McDonald et al. 2016, Higgs et al. 2018, Gann et al. 2019). It is surgery and treatment for the natural environment, that treats and restores the diseased nature to the intact one based on knowledge and information about nature acquired through research done so far, beyond the stage of exploring and revealing its status like a doctor treating a patient with surgery (Lee and You 2001).

The restoration of nature is widely conducted today in both research and practice. In Korea, the term "restoration" has emerged since the 1990s and is now very common. However, its concept and direction are different from those of developed countries that have long conducted research in this field (Lee et al. 2011, An et al. 2014, Lee 2015).

The concepts and procedures of ecological restoration are also provided in textbooks of general ecology and restoration ecology and on the website of the Society of Ecological Restoration International (www.ser.org). However, this principle of restoration tends to be usually ignored in most restoration projects ongoing in Korea. Diagnostic evaluations are often omitted in the restoration projects, and even if introduced, the level and method of restoration are rarely determined based on the results, and most restoration projects are actively carried out regardless of the damage level. Therefore, costs and energy are wasted, and the effect is not significant even after investing a lot of money and energy. Reference information is rarely applied, and restoration practice is carried out by the operator's subjective judgment. In other words, restoration projects without models and without goals are being carried out. Therefore, exotic species that should be completely excluded from the restoration project are often introduced, and it is common for species introduced for restoration to be placed outside of the ecological spatial distribution (strictly speaking, exotic species) or suitable micro habitats for larger ecological functions. Monitoring is conducted, but effective adaptive management is not carried out because the reference information, which is the goal of restoration, is not used at the beginning of the project. In addition, few evaluations have been made of the effects of restoration. Therefore, progress has not been made even if the project continues (Lee et al. 2011, An et al. 2014, Lee 2015).

It is believed that this problem first stems from the lack of awareness of the concept of restoration, which is the process of assisting a recovery; the damaged nature heals itself (Lee et al. 2011, An et al. 2014, Lee 2015, Kim et al. 2021, Lim et al. 2021). We can find the background from that most restoration projects are being carried out just by the active restoration. Another problem is from that reference information, which should be a model in the restoration plan and the basis for determining success or fail of the project after restoration practice is not utilized. This problem is judged to stem from the lack of awareness of the concepts for ecology and 
restoration ecology as most operators of restoration businesses are people engaged in forestry or classical landscaping in the past (Lee et al. 2011, An et al. 2014, Lee 2015).

This study aims to introduce the principles and cases of ecological restoration applied to the National Institute of Ecology, which oversees the nation's ecological research, to promote the correction and development of restoration ecology going in the wrong direction in Korea.

\section{Background for construction of the National Institute of Ecology}

Initially, the Seocheon area, where located on the central western Korea, had a plan to reclaim mudflats and then create a Janghang national industrial complex (Fig. 1). However, a consensus that a new alternative is needed to preserve mudflats and promote regional development at the same time, was formed as the ecological importance of tidal flats has been highlighted. Therefore, the construction of the National Ecological Institute began as an alternative project, which establishes the national research institutes such as the National Institute of Ecology and the National Institute of Marine Biological Resources and the ecological industry complex instead of the construction of Janghang national industrial complex, under an agreement between local and central governments. As such, the construction of a sustainable development model in the region along with the preservation of wetlands is the background for the establishment of the National Institute of Ecology (Lee 2011).

On the other hand, at the national level, the research institute for ecology was needed to cope with the worsening conditions for maintaining biodiversity due to accelerated climate change such as global warming and

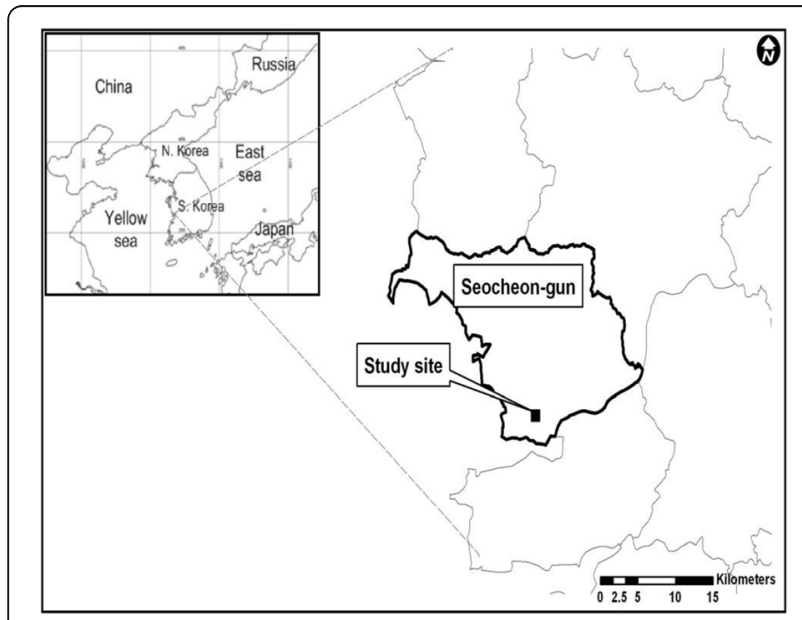

Fig. 1 A map showing the geographic location of the National Institute of Ecology, which is located on Seocheon, central western Korea increased demand for development. In other words, institutions that can conduct comprehensively research, exhibition, and education functions that can directly experience, feel, and learn the importance of ecological conservation and biodiversity while conducting systematic and long-term ecological research to prepare for climate change were required (Lee 2011, NIE 2012).

In other words, the National Institute of Ecology is a national integrated ecological research institute that carries out studies for ecosystem change due to climate change and biodiversity conservation that both central and local governments require, performs ecological education to the public through exhibition of various ecosystem models, and promotes regional development through the ecological industry, which is a future industry (Lee 2011, NIE 2012).

The National Institute of Ecology seeks to minimize the impact on the ecosystem even in the construction process and operation. First of all, the building of the National Institute of Ecology was constructed to drastically reduce energy use by more than $70 \%$ compared to existing buildings with similar building areas. To reach this goal, eco-friendly construction technologies such as triple glass, natural lighting, and renewable energy technologies such as solar light, solar heat, and geothermal were actively introduced. In order to reach this goal in another viewpoint, outdoor spaces were also created by boldly breaking away from the existing scenery-oriented landscaping method and thoroughly accepting the principles of ecological restoration (Lee 2011).

Humans are now facing an environmental crisis such as climate change, which threatens survival of human itself. This crisis is originated from the anti-ecological behavior of human. The National Institute of Ecology is ecological in both background and purpose for establishment, as well as its construction process and operation plan (Lee 2011).

In this regard, the National Institute of Ecology is expected to provide us with wisdom to overcome such an environmental crisis. Here, we would like to introduce the principles of ecology, especially restoration ecology, which forms the central axis of modern ecology, reflected in the construction of the National Institute of Ecology.

\section{Concept of restoration ecology}

Ecological restoration is the process of assisting the recovery of an ecosystem that has been degraded, damaged, or destroyed (SERI 2004, Suding et al. 2015, McDonald et al. 2016, Higgs et al. 2018, Gann et al. 2019). A fundamental distinction between ecological restoration and other forms of ecosystem repair is that ecological restoration seeks to "assist recovery" of a natural or semi-natural ecosystem rather than impose a new 
direction or form upon it. That is, the activity of restoration places an ecosystem on a trajectory of recovery so that it can persist and its species can adapt and evolve (SERI 2004, Suding et al. 2015, McDonald et al. 2016, Higgs et al. 2018, Gann et al. 2019). The basis of ecosystem management in National Institute of Ecology is inducing passive restoration (Lee 2011).

It is the very passive restoration that led to the natural development of stream and surrounding wetlands by creating a waterway in the abandoned rice paddies, which were located between the Yonghwasil pond and the visitor center. We could found that they regain their original feature in the process of succession after abandonment as indeed most rice paddies in Korea were originally converted from floodplains of the river (Lee et al. 2002). And the successional process resembles the spatial distribution of the vegetation, which appears according to the distance from the waterways in the river's riparian zone.

Ecological restoration is commonly used to describe not only a process (i.e., an activity undertaken for a given set of goals) but also the outcome sought for an ecosystem (i.e., its recovery). McDonald et al. (2016) favor the term recovery and define an ecological restoration activity as any activity whose aim it is to ultimately achieve ecosystem recovery, insofar as possible and relative to an appropriate local native model (termed here a reference ecosystem), regardless of the period of time required to achieve the recovery outcome.

It was originally a wetland where the National Institute of Ecology was located, and right before the National Institute of Ecology was established, it was consisted mainly of agricultural fields including rice paddies. In the process creating the National Institute of Ecology, most of the space was left in the process of nature, except in areas where artificial facilities were introduced, and thereby reflected the principles of restoration ecology, which assists recovery process. In particular, we helped the rice paddy return to natural wetland by leaving it in natural process after created just a waterway in the middle of the rice paddy located in the section from the Yonghwasil pond to the visitor center (Photo 1).

\section{The importance of the reference information}

Ecological restoration means to copy the nature by studying a system of the integrate nature (Hough 1984, MacMahon 1987, Aber 1987, Kim et al. 2021, Lim et al. 2021). A reference ecosystem is a model representing the approximate restoration target (Kim et al. 2021, Lim et al. 2021). In the absence of suitable intact ecosystems of the same type surviving close to the targeted site, the reference model can be derived from multiple sources of information about past and present biota and conditions occurring on or near the site; supplemented by information on anticipated changes in environmental conditions that may lead to altered biological assemblages (Doll et al. 2003). A reference ecosystem can serve as the model for planning an ecological restoration project, and later serve as a tool for evaluation of that project (SER 2004, Suding et al. 2015, McDonald et al. 2016, Higgs et al. 2018, Gann et al. 2019). In instances where the object of restoration consists of two or more kinds of ecosystems, the reference can be called the reference landscape or, if only a portion of a local landscape is to be restored, the reference landscape element. The designated ecosystem, landscape, or element can simply be called as the reference. Typically, the reference represents a point of advanced development that lies somewhere along the intended trajectory of the restoration. In other words, the restored ecosystem is eventually expected to emulate the attributes of the reference, and project goals and strategies are developed in light of that expectation. The reference can consist of one or several specified locations that contain model ecosystems, a written description, or a combination of both. Information collected on the reference includes both biotic and abiotic components (SERI 2004, Suding et al. 2015, McDonald et al. 2016, Higgs et al. 2018, Gann et al. 2019).

Restoration ecology is an ecological technique for repairing damaged nature by imitating an intact system of nature. Intact nature means reference information (Kim et al. 2021, Lim et al. 2021). We collected the reference information in well-preserved areas such as national parks. We thoroughly reflected the principles of restoration ecology by applying the reference information in the process of reproducing biomes of major climatic zones around the world (Fig. 2) as well as Korean Peninsula forests (Fig. 3) and wetland including abandoned paddy fields, Ramsar designated wetlands, and backwater wetland of the river (Fig. 4). Blueprints included the reference information for creating wetland of a few types and functional groups of wetland vegetation were shown in Fig. 5. In the process of creating the Korean Peninsula forests, soil ameliorator was applied to help establish the plants that were introduced and to help the subsequent autogenic process (Photo 3). Ecosystem functions and processes, along with the reproduction and growth of organisms, are what cause an ecosystem to be self-renewing or autogenic. A common goal for the restoration of any natural ecosystem is to recover autogenic processes to the point where assistance from restorationists is no longer needed. In this regard, the central role of a restoration practitioner is to initiate autogenic processes. Restoration practitioners commonly assume that autogenic processes will commence once the appropriate species composition and structure have been re-established. This is not always a 

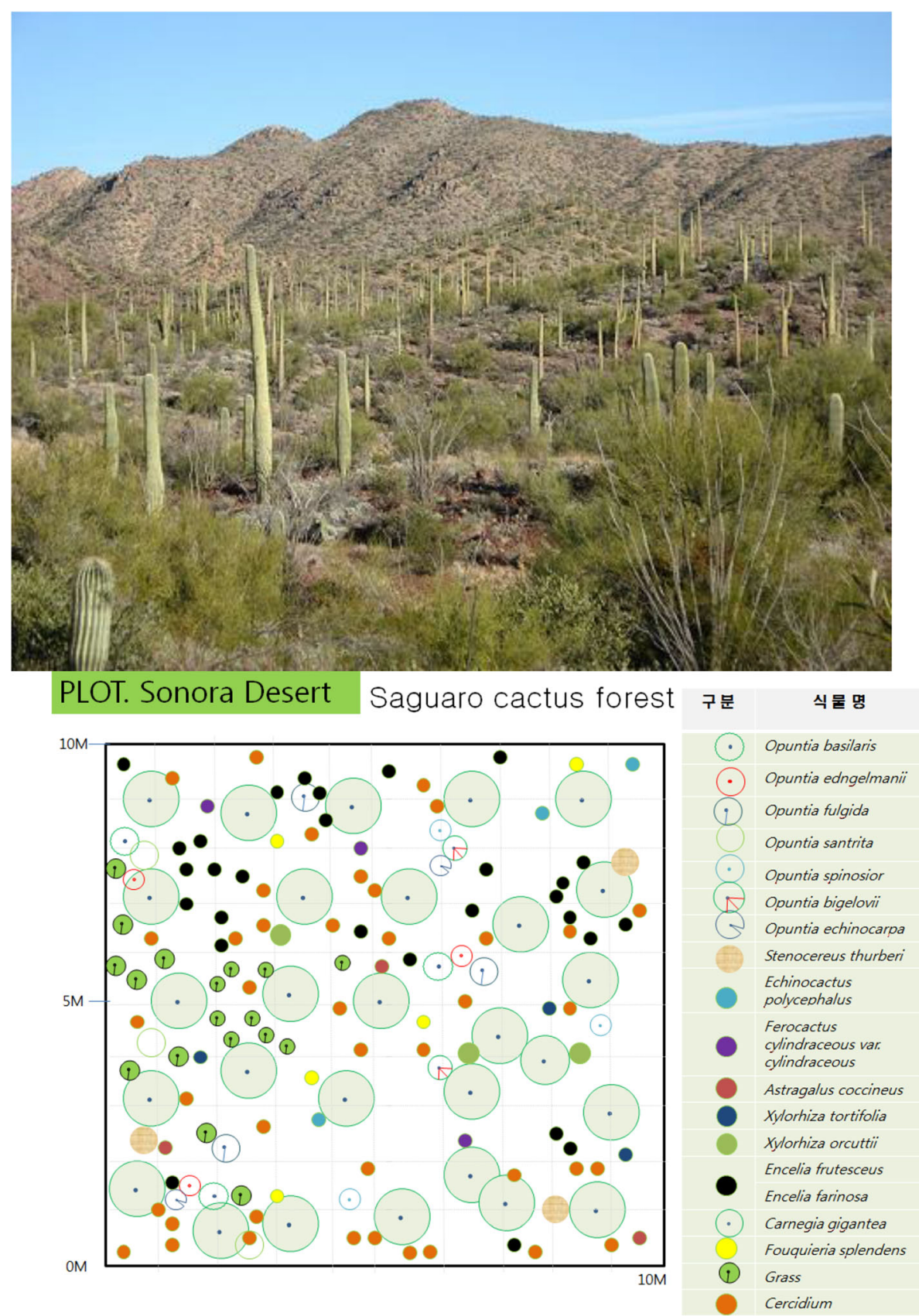

Fig. 2 A photo showing a site view of the Saguaro National Park in Sonora desert and the reference information prepared through field survey for creating the Saguaro cactus stand

valid assumption, but it is a reasonable starting point for ecosystem restoration.

In addition, we introduced mantle vegetation at the edges to reduce the exposure of the restored ecological space to external influences (Fig. 6). This corresponds to the completion of restoration work to keep the restored ecosystem in a stable state (Lee et al. 1998, Lee et al. 2008).

\section{Attributes of restored ecosystems}

An ecosystem has recovered-and is restored-when it contains sufficient biotic and abiotic resources to continue its development without further assistance or subsidy. It will sustain itself structurally and functionally. It will demonstrate resilience to normal ranges of environmental stress and disturbance. It will interact with contiguous ecosystems in terms of biotic and abiotic flows 


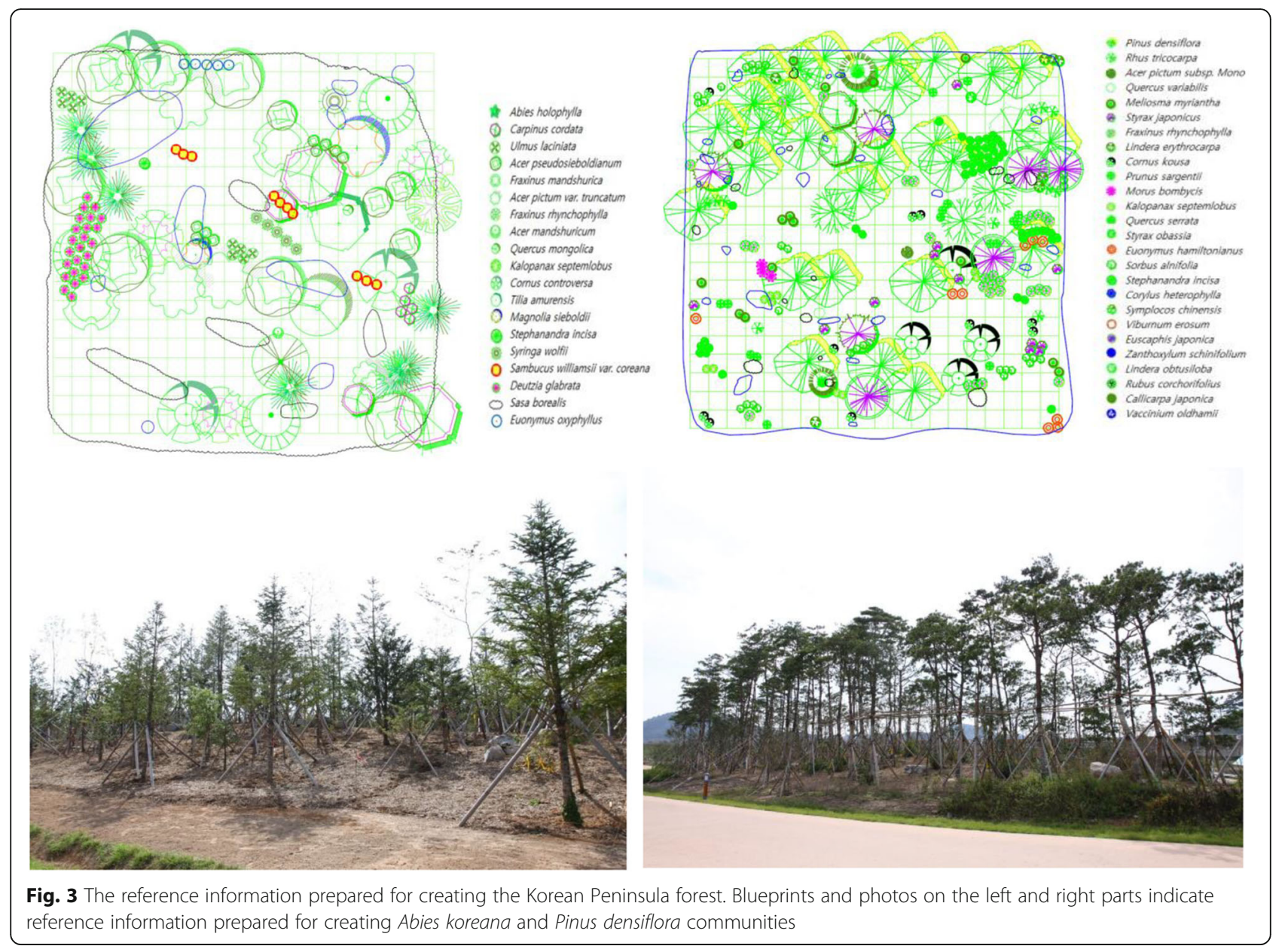

and cultural interactions (SERI 2004, McDonald et al. 2016, Gann et al. 2019).

SERI (2004) suggests the following nine attributes as a basis for determining when restoration has been accomplished. The full expression of all of those attributes is not essential to demonstrate restoration. Instead, it is only necessary for these attributes to demonstrate an appropriate trajectory of ecosystem development toward the intended goals or reference. Some attributes are readily measured but others must be assessed indirectly, including most ecosystem functions, which cannot be ascertained without research efforts. First, the restored ecosystem contains a characteristic assemblage of the species that occur in the reference ecosystem and that provide appropriate community structure. Second, the restored ecosystem consists of indigenous species to the greatest practicable extent. However, in restored cultural ecosystems, allowances can be made for exotic domesticated species and for non-invasive ruderal and segetal species that presumably co-evolved with them. Ruderals are plants that colonize disturbed sites, whereas segetals typically grow intermixed with crop species. Third, all functional groups necessary for the continued development and/or stability of the restored ecosystem are represented or, if they are not, the missing groups have the potential to colonize by natural means. Fourth, the physical environment of the restored ecosystem is capable of sustaining reproducing populations of the species necessary for its continued stability or development along the desired trajectory. Fifth, the restored ecosystem apparently functions normally for its ecological stage of development, and signs of dysfunction are absent. Sixth, the restored ecosystem is suitably integrated into a larger ecological matrix or landscape, with which it interacts through abiotic and biotic flows and exchanges. Seventh, potential threats to the health and integrity of the restored ecosystem from the surrounding landscape have been eliminated or reduced as much as possible. Eighth, the restored ecosystem is sufficiently resilient to endure the normal periodic stress events in the local environment that serve to maintain the integrity of the ecosystem. Finally, the restored ecosystem is selfsustaining to the same degree as its reference ecosystem, and has the potential to persist indefinitely under existing environmental conditions. Nevertheless, aspects of its biodiversity, structure, and functioning may change as part of normal ecosystem development, and may fluctuate in response to normal periodic stress and occasional disturbance 

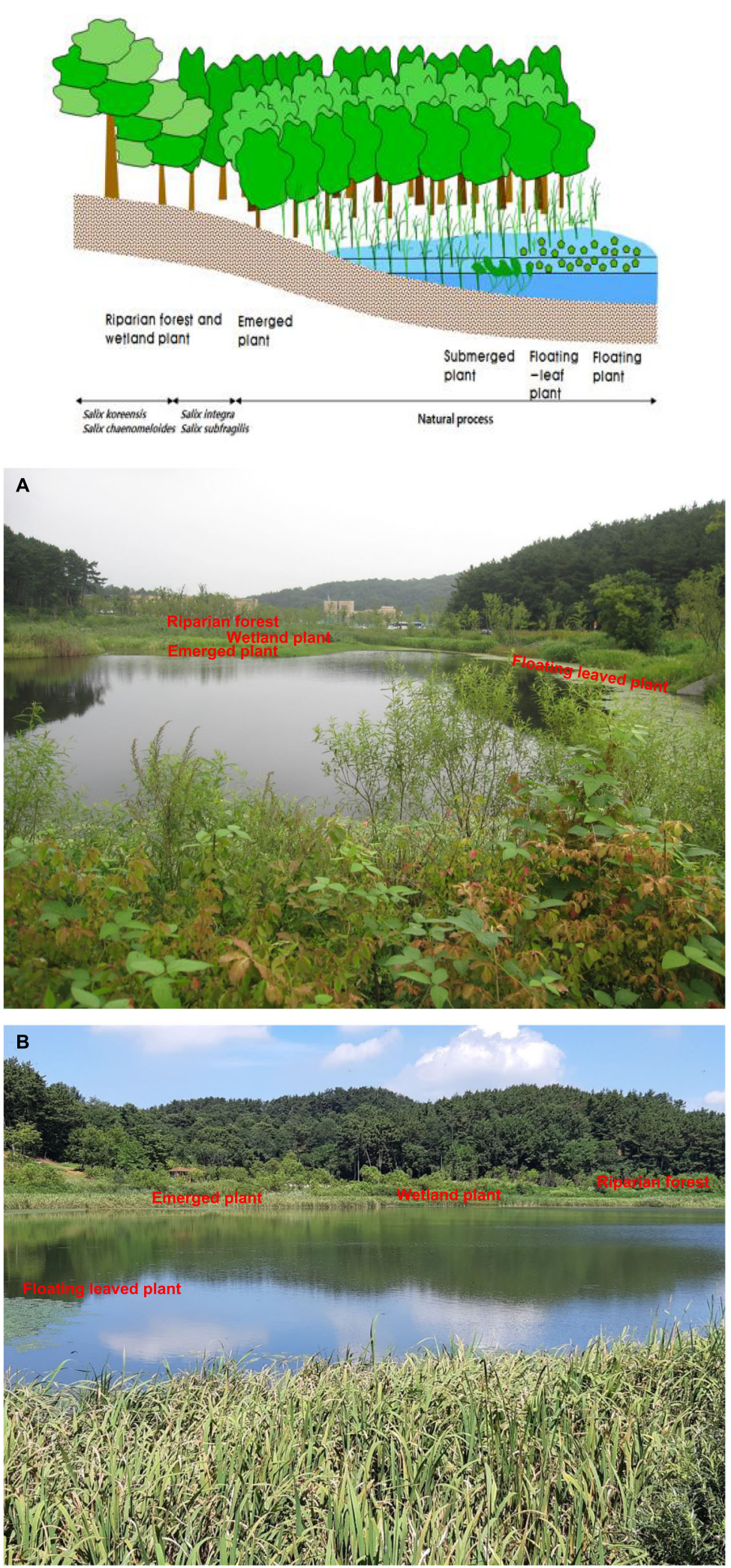

Fig. 4 A schematic diagram (upper) and actual feature of Najeoeo (A) and Yonghwasil (B) ponds showing the spatial distribution of functional groups of the wetland vegetation according to changes in water depth and water table as a reference information for restoring wetlands 


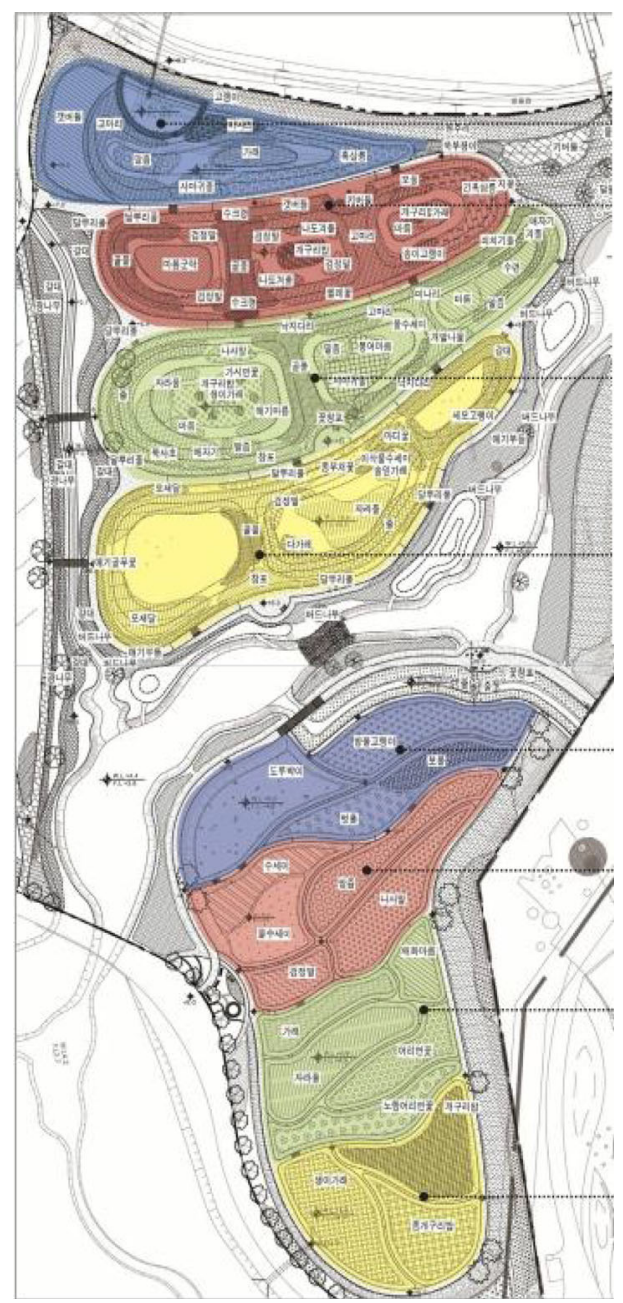

\section{Saemtong reservoi}

Aneilema keisak, Persicaria thunbergii,

Potamogeton crispus, Potamogeton distinctus,

Salix gracilistyla, Sparganium erectum

Abandoned rice paddy

Juncus effuusus var. decipiens, Pennisetum

alopecuroides, Persicaria thunbergii, Phragmites

japonica, Potentilla chinensis, Rosa multiflora,

Sparganium japonicum, Trapa japonica etc.

Ramsar convention

Ceratophyllum demersum, Euryale ferox, Juncus effuusus var. decipiens Penthorum chinense, Salix chaenomeloides, Trapa japonica etc.

\section{Estuary}

Hydrocharis dubia, Phacelurus latifolius, Phragmites communis, Phragmites japonica, Scutellaria dependens, Schoenoplectus triqueter, Zizania latifolia etc.

\section{Emerged plant}

Sagittaria aginashi, Sagittaria sagittifolia subsp.

Leucopetala, Scirpus radicans, Scirpus wichurae

\section{Submerged plant}

Hydrilla verticillata, Luffa aegyptiaca, Myriophyllum

verticillatum, Potamogeton crispus, Vallisneria natans

\section{Leaf-floating plant}

Hydrocharis dubia, Nymphoides indica, Nymphoides peltata, Potamogeton distinctus, Ranunculus kazusensis

\section{Floating plant}

Lemna perpusilla, Salvinia natans, Spirodela polyrhiza

Fig. 5 Blueprint including the reference information for creating several types of wetland (left). The reference information was obtained from Saemtong reservoir, abandoned paddy fields in Goesan, Sangju, and Gokseong, Woopo swamp, and estuary of Nakdong and Han rivers in the first, second, third, and fourth wetlands, respectively. Blueprint including the functional groups of wetland vegetation such as emerged, submerged, leaf-floating, and floating plants were exhibited by reflecting water depth that they grow in their habitats (right)

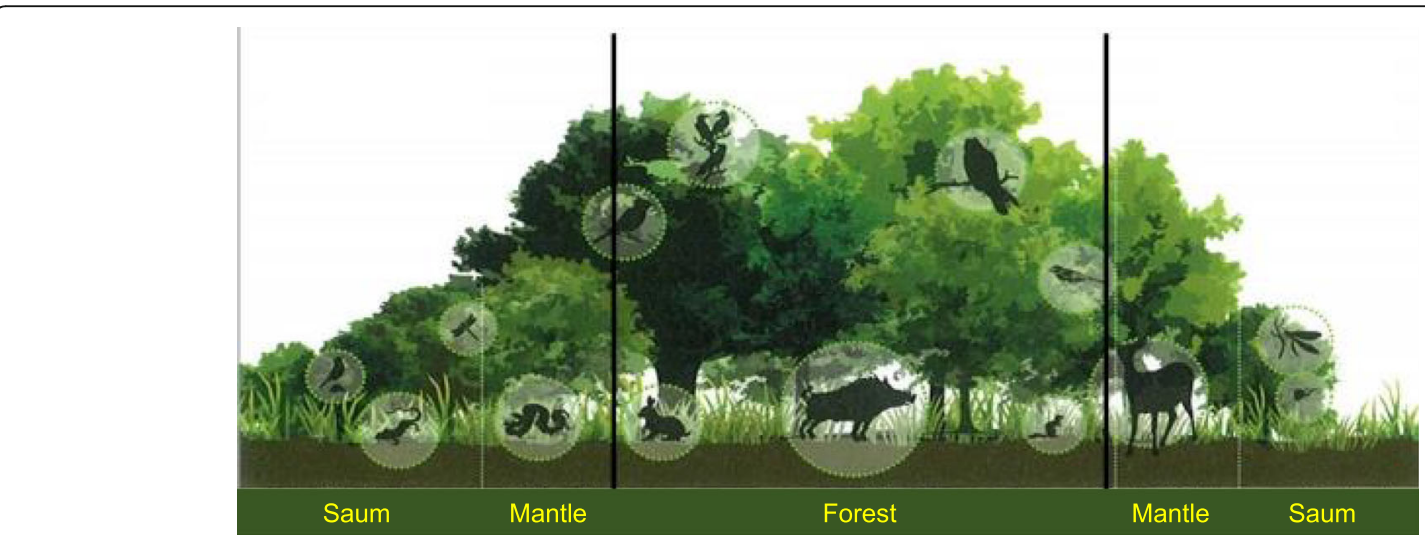

Fig. 6 A diagram showing mantle and saum vegetation introduced at the edges to reduce the exposure of the restored ecological space to external influence 
events of greater consequence. As in any intact ecosystem, the species composition and other attributes of a restored ecosystem may evolve as environmental conditions change.

Forest vegetation and wetlands created at the National Institute of Ecology are relatively well established in a state introduced based on the reference information and are harmonized with the surrounding nature (Temperton et al. 2014, Kim et al. 2014, An et al. 2016). In this regard, it can be assessed that it follows the trajectory of ecological restoration. However, the vegetation types introduced beyond the climatic condition of the region for exhibition, for example, warm temperature evergreen forest and sub-alpine forest, are having a difficulty for establishing. These results make us realize that the system of nature should be respected in future ecological restoration.

\section{Preparation for realizing true restoration}

Ecological restoration should be integrated into larger programs to realize true restoration. Ecological restoration is sometimes only one of many elements within a larger public or private program, such as programs for watershed management, ecosystem management, and nature conservation. An ecosystem has recovered-and is restored-when it contains sufficient biotic and abiotic resources to continue its development without further assistance or subsidy. It will sustain itself structurally and functionally. It will demonstrate resilience to normal ranges of environmental stress and disturbance. It will interact with contiguous ecosystems in terms of biotic and abiotic flows and cultural interactions (Hobbs and Norton 1996, SERI 2004, Suding et al. 2015, McDonald et al. 2016, Higgs et al. 2018, Gann et al. 2019).

The restored ecosystem should be suitably integrated into a larger ecological matrix or landscape, with which it interacts through abiotic and biotic flows and exchanges. True restoration requires a restoration of the landscape-level as such. Landscape-scale restoration is the ecological restoration efforts that incorporate landscape-level processes, such as the flow of genes, individuals, materials, and energy across large areas that may not be possible in smaller projects (Holl et al. 2003). Landscape-scale restoration includes large, contiguous, or fragmented areas to ensure ecological connectivity (Menz et al. 2013, von Holle et al. 2020).

In order to ensure connectivity during the construction of the National Institute of Ecology, we moved the local road 6 and high-voltage power lines to underground (Photo $1 \mathrm{~A}$ and $\mathrm{B}$ ). On the other hand, most lowlands do not have intact nature due to excessive land use because Korea has less land available for human use as a mountainous country. However, the lowlands of the DMZ, which were left in the natural process for more than 70 years after the Korean War, have been restored and preserved those landscape elements. The National Institute of
Ecology created a DMZ landscape that grassland wetlands, shrubby wetland, willow (Salix koreensis) stand, alder (Alnus japonica) stand, Quercus aliena stand, and Quercus serrata stand were followed continuously without any fragmentation by imitating this feature of Korean DMZ (Photo 1 DMZ landscape). We planned to pursue this true restoration of the level of landscape in the process of creating the National Institute of Ecology.

Applied nucleation (i.e., establishing small patches of shrubs and/or trees to serve as focal areas for recovery) is a strategy that uses principles of colonization of nonforested landscapes by woody vegetation to restore forest cover. Applied nucleation is a restoration technique that seeks to facilitate woody-plant establishment by attracting birds or other animals that may introduce seeds of dispersal-limited species (Corbin et al. 2016).

The Yonghwasil pond of a rectangular shape was transformed into a natural oval shape, the steep slope of the levee was gently trimmed, and riparian vegetation was introduced to pursue a shape similar to a natural wetland (Photo 2). Rounded shape minimizes the edge-to-area ratio and the center is farther from the edge. Fragmented habitat has a greater amount of edge and the center is closer to an edge. Fragmentation limits a species' potential for dispersal and colonization (Pfeifer et al. 2017). The gentle trimming of slopes (Photo 2A), the introduction of islands (Photo $2 \mathrm{~b}$ ) and perch poles (Photo $2 \mathrm{C}$ ), and the creation of a riparian vegetation (Photo 2D) in the Yonghwasil pond correspond to ecological restoration that improves the quality of the habitat of animals including birds. Furthermore, it corresponds to a kind of nucleation that attracts birds here and leads them to their role as biological engineers in future restoration. In addition, considered kinds of the restored landscape elements and the spatial range of space treated restoratively, this restoration strategy corresponds to the landscape-level restoration.

Change of wetland vegetation established in the $\mathrm{Na}$ tional Institute of Ecology resembled the typical trend of early successional stage occurring in the abandoned rice paddy and consequently, it was estimated that successful restoration is under progress (Lee et al. 2002). Restoration under progress in an ecological pond, where artificial aid in the least level was added, could be evaluated as successful as well. In particular, successful establishment of buffering vegetation, which can play diverse ecological functions, could be evaluated as significant restoration effect (An et al. 2016).

\section{Ecosystem services of the nature established in the National Institute of Ecology}

One of the goals of restoration might be to provide specified natural goods and services for social benefit in a sustainable manner. In this respect, the restored ecosystem serves as natural capital for the accrual of these 
goods and services. The result of evaluation on the net ecosystem production (NEP) showed that the nature established in the National Institute of Ecology could ab-

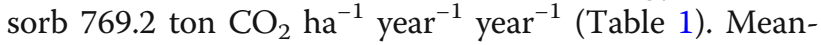
while, carbon dioxide emissions from the energy used by the National Institute of Ecology were calculated to be 870 ton $\mathrm{CO}_{2} \mathrm{ha}^{-1}$ year $^{-1}$ year $^{-1}$ (NIE 2012). Combined with the results, the National Institute of Ecology campus is estimated to be able to offset about $88 \%$ of the carbon dioxide emitted for the operation of the National Institute of Ecology. This carbon absorption capability is significantly higher than the country's total carbon dioxide offsetting capability (about 6\%) and higher than the urban area as well as the typical rural area of Seocheongun (about 12\%) (Kim et al. 2014).

Another goal might be for the restored ecosystem to provide habitat for rare species or to harbor a diverse genepool for selected species. The National Institute of Ecology currently has a total of 1349 species including 578 plants, 576 insects, 16 amphibian and reptiles, 108 birds, 13 mammals, 55 benthic invertebrates, and 21 fishes. Endangered species of six plants, one insect, two amphibians, eight birds, and two mammals are included among them (NIE 2020).

Other possible goals of restoration might include the provision of esthetic amenities or the accommodation of activities of social consequence, such as the strengthening of a community through the participation of individuals in a restoration project (SERI 2004, McDonald et al. 2016, Gann et al. 2019). Currently, about a million visitors visit the National Institute of Ecology every year and National Institute of Ecology operates various ecology education programs.

Combined abovementioned results, the National Institute of Ecology is considered to be displaying significant ecosystem service. In those respects, it is evaluated that the National Institute of Ecology displays the original purposes of the construction.

\section{Conclusion}

The environmental problem refers to a state in which the ecological function of the environment is destroyed and thus the order and laws of the ecosystem are collapsed due to the influence of human activities. In other words, the environmental problem arose due to a functional imbalance between the environmental stress increased as the size of human population who is one of the diverse biological components of the environment, increase significantly and they pursue a highly civilized

Table 1 Carbon budget of the National Institute of Ecology

\begin{tabular}{|c|c|c|}
\hline $\begin{array}{l}\mathrm{CO}_{2} \text { emission } \\
\left(\mathrm{TCO}_{2} \quad \text { year }^{-1}\right) \\
\end{array}$ & 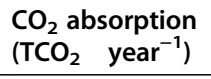 & $\begin{array}{l}\mathrm{CO}_{2} \text { offset } \\
\text { (\%) }\end{array}$ \\
\hline 870.0 & 769.2 & 88.4 \\
\hline
\end{tabular}

life, and nature to buffer it. Such problems were first detected at the local level, such as cities, and nowadays, when it is accumulated, they are also detected at the global level like climate change. Consequently, a functional balance between sources of environmental stress and their sinks in order to solve these problems should be restored in order to solve these problems. The carbon neutrality policy, the International Union for Conservation of Nature and Natural Resources (IUCN)'s Ecosystem based solutions, and the United Nations (UN) Decade on Ecosystem Restoration as measures to address climate change, are among these solutions.

The environment is a system that biodiversity formed by a variety of creatures and their habitat are combined through a harmonious relationship. Ecology deals with the interrelationship between biological components of the environment, animals including humans, plants, and microorganisms, and various environmental factors that make up their living space, the non-biological environment. The role of ecology as a living science and practical science is attracting attention at a time when environmental issues emerge as a major concern of mankind, and it is recognized that humans are at the center of such problems. In particular, there are growing calls for the introduction and application of ecological concepts and principles in all human activities in order to recognize the background of environmental problems and derive their solutions.

The National Institute of Ecology was prepared to accommodate these needs of the society. Such demands are expected to increase further in the future at a time when global environmental problems are increasing and serious, including climate change and biodiversity loss. It is hoped that the principles and concepts of ecology, especially restoration ecology, which was reflected in the construction of Korea's National Institute of Ecology, would be reflected in all projects that manage the imbalanced environments as well as the construction of similar institutions.

\section{Abbreviations}

DMZ: Demilitarized zone; IUCN: International Union for Conservation of Nature and Natural Resources; NEP: Net ecosystem production; UN: United Nations

\section{Supplementary Information}

The online version contains supplementary material available at https://doi. org/10.1186/s41610-021-00187-w.

Additional file 1: Photo 1. Photos showing the principle and concepts of restoration ecology reflected for creating the National Institute of Ecology. The No. 6 local road (A) and the high-pressure power line (B), which intersect between the research space on the right $(C)$ and the exhibition space on the left (D), were moved underground to pursue ecological connections between the both spaces. Korean peninsula forest, wetland, and subalpine vegetation were prepared to exhibit the reference information, which can be applied for restoration of forest, wetland, 
and subalpine ecosystems in Korea. DMZ landscape expressed landscape elements such as herbaceous wetland, shrubby wetland, willow stand, alder stand, Quercus aliena stand, and Quercus serrata stand, which could be established from plain land to lower slope but disappeared due to excessive land use in most areas of the Korean peninsula. Passive restoration was applied to recover the abandoned rice paddy to its original stream. Photo 2. Yonghwasil pond improved by the restorative treatment such as the gentle trimming of slopes (A), the introduction of islands (B) and perch poles (C), and the creation of a riparian vegetation (D). Photo 3. Soil ameliorator was applied to help establish the plants introduced and to help the subsequent autogenic process.

\section{Acknowledgements}

Not applicable.

\section{Authors' contributions}

LCS designed the study. LCS, KAR, LBS, and SJW collected and analyzed the data. KAR and LCS wrote the initial draft of the manuscript. All authors read and approved the final manuscript.

\section{Funding}

This work was supported by a research grant from Seoul Women's University (2021).

\section{Availability of data and materials}

The datasets generated during and/or analyzed during the current study are available from the corresponding author on reasonable request.

\section{Declarations}

Ethics approval and consent to participate

Not applicable.

\section{Consent for publication}

Not applicable.

\section{Competing interests}

The authors declare that they have no competing interests.

\section{Author details}

'Graduate School of Seoul Women's University, Seoul Women's University, 621 Hwarang-no, Nowon-gu, Seoul 01797, Republic of Korea. 'Division of Chemistry and Bio-Environmental Sciences, Seoul Women's University, 621 Hwarang-no, Nowon-gu, Seoul 01797, Republic of Korea.

Received: 21 May 2021 Accepted: 8 July 2021

Published online: 31 July 2021

\section{References}

Aber JD. Restored forests and the identification of critical factors in species-site interactions. In: Jordan WR, Gilpin ME, Aber JD, editors. Restoration ecology. A synthetic approach to ecological research. Cambridge, UK: Cambridge University Press; 1987. p. 241-50.

An JH, Lim CH, Lim YG, Nam KB, Lee CS. A review of restoration project evaluation and post management for ecological restoration of the river. Journal of Restoration Ecology. 2014;4:15-34 [Korean Literature].

An JH, Lim CH, Lim YK, Nam KB, Pi JH, Moon JS, Bang JY, Lee CS. 2016. Development and application of a model for restoring a vegetation belt to buffer pollutant discharge. Journal of Korean Society on Water Environment 32:205-15. [Korean Literature]

Aronson J, Florest C, Le Floc'h E, Ovalle E, Pontanier R. Restoration and rehabilitation of degraded ecosystems in arid and semi-arid lands. I. A view from the south. Restor Ecol. 1993;1:8-17 https://doi.org/10.1111/j.1526-100x. 1993.tb.00004.x.

Berger JJ. Ecological restoration and non-indigenous plant species: a review. Restor Ecol. 1993;1 (2):74-82. https://doi.org/10.1111/j.1526-100X.1993. tb00012.x.

Corbin JD, Robinson GR, Hafkemeyer LM, Handel SN. A long-term evaluation of applied nucleation as a strategy to facilitate forest restoration. Ecol Appl. 2016;26(1):104-14. 27039513. https://doi.org/10.1890/15-0075.
Doll BA, Grabow GL, Hall KR, Halley J, Harman WA, Jennings GD, et al. Stream restoration: a natural channel design handbook, NC Stream Restoration Institute. Raleigh: NC State University; 2003.

Gann GD, Lamb D. Ecological restoration: a mean of conserving biodiversity and sustaining livelihoods (version 1.1). Society for Ecological Restoration International. Tucson, Arizona, USA: IUCN, Gland, Switzerland; 2006.

Gann GD, McDonald T, Walder B, Aronson J, Nelson CR, Jonson J, et al. International principles and standards for the practice of ecological restoration. Second edition. Restor Ecol. 2019;27(S1):S1-S46.

Higgs E, Harris J, Murphy S, Bowers K, Hobbs R, Jenkins W, et al. On principles and standards in ecological restoration. Restor Ecol. 2018;26(3):399-403. https://doi.org/10.1111/rec.12691.

Hobbs RJ, Norton DA. Towards a conceptual framework for restoration ecology. Restor Ecol. 1996;4(2):93-110. https://doi.org/10.1111/j.1526-100X.1996.tb00112.x.

Holl KD, Crone EE, Schultz CB. Landscape restoration: moving from generalities to methodologies. Bioscience. 2003;53(5):491-502. https://doi.org/10.1641/ 0006-3568(2003)053[0491:LRMFGT2.0.CO;2.

von Holle B, Yelenik S, Gornish ES. Restoration at the landscape scale as a means of mitigation and adaptation to climate change. Current Landscape Ecology Reports. 2020;5(3):85-97. https://doi.org/10.1007/s40823-020-00056-7.

Hough M. City form and natural process. London, UK: Croom Helm; 1984. p. 279.

Kim GS, Lim YK, An JH, Lee JS, Lee CS. Carbon budget in campus of the National Institute of Ecology. KJEE. 2014;47(3):167-75. https://doi.org/10.11614/KSL.2 014.47.3.167.

Kim AR, Lim BS, Seol J, Lim CH, You YH, Lee WS, et al. Diagnostic assessment and restoration plan for damaged forest around the Seokpo Zinc Smelter. Central Eastern Korea Forests. 2021;2021(12):663 https://doi.org/10.3390/f12060663.

Lee CS. Why the central government has to manage the National Institute of Ecology? Korean J. Restor Ecol. 2011;2(2):101-9.

Lee CS. Role and task of restoration ecology in changing environment. Natl Acad Sci. 2015;5:481-527 [Korean Literature].

Lee CS, You YH. Creation of an environmental forest as an ecological restoration. The Korean Journal of Ecology. 2001;24:101-9.

Lee CS, Cho HJ, Moon JS, Kim JE, Lee NJ. Restoration and landscape ecological design to restore Mt. Nam in Seoul, Korea as an ecological park. Kor J Ecol. 1998:21:723-33.

Lee CS, You YH, Robinson GR. Secondary succession and natural habitat restoration in abandoned rice fields of central Korea. Restor Ecol. 2002;10: 306-14 https://doi.org/10.1046/j.1526-100x.2002.00003.x.

Lee CS, Cho YC, Lee AN. Restoration planning for the Seoul metropolitan area, Korea. In: Carreiro MM, Wu J, Song YC, editors. Ecology, Planning, and Management of Urban Forests. New York, USA: Springer; 2008. p. 393-419.

Lee CS, Jeong YM, Kang HS. Concept, direction, and task of ecological restoration. Journal of Restoration Ecology. 2011;2:59-71.

Lim CH, Pi JH, Kim AR, Cho HJ, Lee KS, You YH, et al. Diagnostic evaluation and preparation of the reference information for river restoration in South Korea. Int J Environ Res Public Health. 2021;2021(18):1724 https://doi.org/10.3390/ ijerph18041724.

MacMahon JA. Disturbed lands and ecological theory: an essay about a mutualistic association. In: Jordan WR, Gilpin ME, Aber JD, editors. Restoration ecology. Cambridge, UK: Cambridge University Press; 1987. p. 221-40.

McDonald T, Gann G, Jonson J, Dixon K. International standards for the practice of ecological. Soil-Tec, Inc.,@ Marcel Huijser, Bethanie Walder. Washington, DC, USA: Society for Ecological Restoration; 2016.

Menz MHM, Dixon KW, Hobbs RJ. Hurdles and opportunities for landscape-scale restoration. Science. 2013;339(6119):526-7. https://doi.org/10.1126/ science.1228334.

National Research Council (NRC). Committee on the Comparative Costs of Rock Salt, \& Calcium Magnesium Acetate (CMA) for Highway Deicing. Highway deicing: comparing salt and calcium magnesium acetate (Vol. 235). Washington, DC, USA: Transportation Research Board; 1991.

NIE (National Institute of Ecology). Operation plan of the National Institute of Ecology. Gwacheon: National Institute of Ecology; 2012.

NIE (National Institute of Ecology). Another Korean Peninsula Ecosystem, National Institute of Ecology. Seocheon: National Institute of Ecology; 2020.

Pfeifer M, Lefebvre V, Peres CA, Banks-Leite C, Wearn OR, Marsh CJ, et al. Creation of forest edges has a global impact on forest vertebrates. Nature. 2017 Nov 9:551(7679):187-91. https://doi.org/10.1038/nature24457.

SERI (Society Ecological Restoration International Science \& Policy Working Group). The SER International Primer on Ecological Restoration. 2004. http:// www.ser-rrc.org/resource/the-ser-international-primer-on/. 
Suding K, Higgs E, Palmer M, Callicott B, Anderson CB, Baker M, et al. Committing to ecological restoration: efforts around the globe need legal and policy clarification. Science. 2015;348:6235.

Temperton VM, Higgs E, Choi YD, Allen E, Lamb D, Lee CS, et al. Flexible and adaptable restoration: an example from South Korea. Restor Ecol. 2014;22(3): 271-8. https://doi.org/10.1111/rec.12095.

Walker LR, Walker J, Hobbs RJ, editors. Linking restoration and ecological succession. New York, USA: Springer; 2007. https://doi.org/10.1007/978-0-3 87-35303-6.

\section{Publisher's Note}

Springer Nature remains neutral with regard to jurisdictional claims in published maps and institutional affiliations.

Ready to submit your research? Choose BMC and benefit from:

- fast, convenient online submission

- thorough peer review by experienced researchers in your field

- rapid publication on acceptance

- support for research data, including large and complex data types

- gold Open Access which fosters wider collaboration and increased citations

- maximum visibility for your research: over $100 \mathrm{M}$ website views per year

At $\mathrm{BMC}$, research is always in progress.

Learn more biomedcentral.com/submissions 